\title{
Valor nutricional de forraje de Pízamo (Erythrina glauca) ensilado con diferentes niveles de melaza y harina de arroz
}

\section{Nutritional value of silage Erythrina glauca forage with different levels of molasses and rice flour}

\author{
Orlando Ordoñez R. ${ }^{1}$, Giovana Díaz LI. ${ }^{1}$ y Ligia Roa V. ${ }^{2}$ \\ ${ }^{1}$ Médicos Veterinarios Zootecnistas de la Universidad de los Llanos \\ ${ }^{2} Z$ Zootecnista MSc., Docente de la Universidad de los Llanos \\ mroa@unillanos.edu.co
}

Recibido 09 de Noviembre de 2009, aprobado 01 de Diciembre 2010

\section{RESUMEN}

El objetivo de esta de investigación fue evaluar el ensilaje de forraje de Pízamo (Erythrina glauca) en su calidad nutricional, para ser utilizado posteriormente en la alimentación animal de en el Piedemonte Llanero de Colombia. Se preparó ensilaje de forraje de Pízamo, en silo-bolsa con tres niveles de melaza: 10\%, $15 \%$ y $20 \%$, se tomó la mitad del material picado al cual se le había aplicado los diferentes niveles de melaza y se le adicionó un 3\% de harina de arroz por tratamiento, quedando la otra mitad del material sin harina, conformando así las diferentes alternativas del ensilaje, para ser analizados en cuatro tiempos de maduración: inicial, treinta, sesenta y noventa días; con tres repeticiones cada uno; conformando un diseño experimental completamente al azar con un arreglo factorial de $3 X 4 X 2$, siendo respectivamente para tratamientos, tiempos y adición de harina de arroz: Se utilizó análisis de varianza y prueba de Tukey. Las variables evaluadas fueron: Materia seca, proteína, fibra cruda, grasa, extracto no nitrógenado (ENN), cenizas, fibra detergente neutro (FDN), fibra detergente ácido (FDA) y degradabilidad ruminal de la materia seca (DMS). El contenido de materia del ensilaje se aumentó $(P<0.05)$ cuando se incrementaron los niveles de melaza y se adicionó harina de arroz, mientras que el tiempo de maduración no influyó $(P>0.05)$ en el contenido de MS. El contenido de proteína se disminuye $(\mathrm{P}<0.05)$ a medida que aumenta el tiempo de maduración, pero se incrementa $(P<0.05)$ cuando se adiciona harina de arroz. La fibra cruda, la FDN y la FDA se disminuyeron $(P<0.05)$ a medida que se 
incrementaba el tiempo de maduración. Lo contrario sucedió con la DMS a las 72 horas, la cual se fue incrementado $(P<0.05)$ a medida que se aumentaba el tiempo de maduración. La DMS en las diferentes horas de degradación fue mínima, observándose un comportamiento similar $(P>0.05)$ en cada una de las horas evaluadas $(6,12,24,48$ y 72). La DMS fue rápida en las primeras 6 horas, llegando a un $39 \%$, promedio de todos los tratamientos, el incremento en las siguientes horas fue: $2 \%, 8 \%, 11 \%$ y $13,7 \%$, respectivamente, lo cual indica que la degradación fue lenta después de las 6 horas hasta las 72 horas. El contenido de grasa y cenizas no se afectó con ningún tratamiento. Se puede concluir que la fibra cruda, la FDN, FDA se afectan con la fermentación de los microorganismos, puesto que rompen las paredes celulares, ocasionando una disminución, lo cual permite una mayor degradabilidad en el rumen.

Palabras claves: Erythrina glauca, ensilaje, calidad nutricional.

\begin{abstract}
This investigation evaluated the silage of Erythrina glauca forage in its nutritional quality, to be used later on in the animal feeding of in Colombia. The Erythrina glauca silage, was pack in silage bag was added to forage three levels of molasses $(10 \%, 15 \%$ and $20 \%$ ), besides, was added $3 \%$ of flour of rice by treatment, being the other half of the forage without flour, the silaje, was analyzed in four times of maturation: 0, 30, 60 y 90 days; with three repetitions each one. The trial was randomized completely to the chance with a factorial arrangement of $3 \times 4 \times 2$, being respectively for treatments, and times of maduration and addition of flour of rice: It was used variance analysis and test of Tukey. The evaluated variables were: Dry matter, protein, raw fiber, fat, non-nitrogenaus extract, ash, the fiber in the neuter detergent (NFD), fiber in the acid detergent (AFD) and degradation in the rumen of the dry matter (DDM). The content of matter of the silage increased $(P<0.05)$ when the levels of molasses were increased and flour of rice was added, while the time of maturation did not influence $(P>0.05)$ on the $D M$ content. The protein content decreased $(P<0.05)$ as it increases the time of maturation, but it is increased $(P<0.05)$ when flour of rice is added. The raw fiber, the NFD and the AFD
\end{abstract}


decreased $(P<0.05)$ as the time of maturation was increased. The opposite happened to the DDM at the 72 hours, which was increased $(P<0.05)$ as it increased the time of maturation. The DDM in the different hours of degradation was minimum, being observed an alike result $(P>0.05)$ in each one of the evaluated hours $(6,12,24,48$ and 72) The DDM was quick in the first 6 hours, until $39 \%$. The increment in the following hours was: $2 \%, 8 \%, 11 \%$ and $13,7 \%$, respectively, that which indicated that the degradation was slow after the 6 hours until the 72 hours, the fat and ashy didn't affect any treatment. Was concluded that the raw fiber, the NFD, AFD were affected the fermentation of the microorganisms, since they break the cellular walls, causing a decrease, that which allows a bigger degradation in the rumen.

Keywords: Erythrina glauca, silage, nutritional quality.

\section{INTRODUCCIÓN}

Uno de los problemas más serios de la ganadería es la disminución de la disponibilidad y calidad del pasto durante la época de sequía. La conservación de especies de alta producción de biomasa, a través del ensilaje, se presenta como una alternativa para asegurar el suministro permanente de alimento en las cantidades requeridas por el animal; es así como se han venido realizando prometedores estudios con la utilización de árboles forrajeros aprovechando su excelente adaptación y producción de biomasa. Los árboles forrajeros en su mayoría tienen buena aceptación y calidad nutricional para los animales, tal es el caso del Pízamo (Erythrina glauca), que se puede utilizar como complemento en un programa de alimentación para ganado, por lo tanto se propone el ensilaje de este forraje, con el fin de aprovechar las bondades que proporciona en un sistema silvopastoril (Chacón, 2000).

Sánchez et al., (1999) definen a los ensilajes como un proceso anaeróbico cuya finalidad es conservar las calidades nutricionales de los forrajes, en el caso del Pízamo que es una leguminosa se recomienda cortar las ramas y hojas a una longitud entre 1,5 a $3 \mathrm{~cm}$, para facilitar el apisonado y por lo tanto la expulsión de aire, de acuerdo a las experiencias se considera que la 
humedad optima del forraje debe estar entre 70 a $73 \%$. Garcés et al., (2004) argumentan que esta humedad se puede determinar directamente en el campo formando una bola en la mano y comprimirla, al abrir la mano sí la bola retiene su forma y queda poca humedad en la mano, entonces el forraje tiene una humedad adecuada para ensilar. En caso de que la bola se expanda rápidamente y no se observa humedad el forraje está demasiado seco y por lo tanto va a afectar la calidad del ensilado. Estos mismos autores reportan que para evitar las pérdidas en el ensilaje es necesario extraer todo el aire y hacer un perfecto tapado y sellado, teniendo presente que la calidad nutricional del forraje es fundamental para la calidad del producto final el ensilaje, es así que Roa et al., (1999) en investigaciones con Pízamo determinaron que la degradabilidad ruminal de la fibra detergente neutro (FDN) y nitrógeno total (NT) a las 72 horas para el Pízamo fue de $27 \%$ y 59\% respectivamente. El nitrógeno en las primeras cuatro horas tiene una degradación rápida que llega al 33\%, en las siguientes horas es más lenta su degradación.

Con relación a la calidad nutricional del Pízamo, Roa y Céspedes (1999), determinaron su contenido de proteína (18\%), FDN (51\%) y fibra detergente ácido (FDA), 38.5\%. Además trabajaron con ovinos africanos a los que se les suministro este árbol, los cuales obtuvieron una ganancia diaria de peso (133 gramos), superior a la observada con matarratón (Gliricidia Sepium) que fue 128 gramos. En investigaciones con vacas doble propósito, Roa et al. (2002), suministraron como suplemento Pízamo, encontraron que la producción de leche se incrementó en un $20 \%$ en comparación con los animales no suplementados. También analizaron las degradabilidades ruminales a las 72 horas de la materia seca (DMS): $33.8 \%$, DFDN: $23.9 \%$ y DNT: $53.5 \%$. Esta investigación busca valorar la calidad nutricional del ensilaje de Pízamo (Erythrina glauca) con diferentes niveles de melaza y harina de arroz utilizando el sistema de silo-bolsa por su facilidad de elaboración y de transporte. 


\section{MATERIALES Y MÉTODOS}

La investigación se realizó en el Municipio de Villavicencio, vereda Barcelona en la granja de la Universidad de los Llanos. Esta zona tiene una altitud de 465 metros sobre el nivel del mar, temperatura promedio de 27 grados centígrados y precipitación anual entre 1900 y 3250 milímetros. Se recogió el material vegetativo del árbol forrajero Pízamo (Erythrina glauca) del vivero establecido en la Universidad de los Llanos y de algunas fincas del Municipio de Villavicencio. Este fue seleccionado y picado en partículas de 2-3 centímetros de longitud, se pesó y se procedió a aplicar la melaza en cantidad de 10\%, $15 \%$ y $20 \%$ para cada tratamiento respectivamente, luego se guardó utilizando el sistema silo-bolsa. A los tres niveles de melaza se les adicionó 3\% de harina de arroz con el fin de comparar el efecto cuando no se utilizó harina de arroz.

Los tratamientos se introdujeron en bolsas de un plástico grueso (calibre 7), este forraje picado fue apisonado teniendo la precaución de llenar muy bien los extremos inferiores para evitar que quedaran burbujas de aire atrapadas en la parte inferior de la bolsa, cuando la bolsa estuvo llena se cerró herméticamente la bolsa interior, tratando de extraer la mayor cantidad posible de aire con ayuda de una aspiradora y luego se introdujo en un saco de polipropileno quedando protegido el plástico; posteriormente se cerró y se almacenó en un sitio cubierto. Se tomaron cuatro tiempos de maduración cada 30 días, quedando conformados estos con un tiempo inicial al momento de ensilar, otro a los 30 días, el siguiente a los 60 días y finalmente a los 90 días.

Los análisis de los tratamientos realizados en el Laboratorio de Nutrición fueron: proximal (materia seca, cenizas, grasa, proteína, fibra cruda, extracto nitrogenado siguiendo la metodología de AOAC, 2006). También se realizaron pruebas de degradabilidad ruminal según la metodología actualizada por Godden et al., (2000) y Mertens, (2002).

Se utilizaron bolsas de dacrón de $20 \times 10$ centímetros con un poro promedio de 40 micras aproximadamente. Las bolsas se secaron previamente a 60 grados centígrados durante 24 horas con el fin de colocarlas a peso constante. En 
cada bolsa se colocó 5 gramos de tratamiento por duplicado para cada tiempo. Las incubaciones en el rumen se realizaron a las 6, 12, 24, 48 y 72 horas, para determinar la degradación de la materia seca (DMS).

A los datos se les realizó un análisis de varianza, se utilizó un diseño experimental completamente al azar con un arreglo factorial de $3 \times 4 \times 2$, siendo respectivamente para tratamientos, tiempos y adición de harina de arroz, se colocaron tres repeticiones por tratamiento para un total de 72 unidades experimentales, se utilizó la prueba de Tukey para comparación de medias.

\section{RESULTADOS Y DISCUSIÓN}

El contenido de materia del ensilaje se aumentó cuando se incrementaron los niveles de melaza (Tabla1), siendo superior $(P<0.05)$ cuando se adicionó el $20 \%$ de melaza en comparación con los otros dos niveles (15 y 10\%), estos resultados concuerdan con los reportados por Roa, (2004) quien observó que cuando se utiliza mayor proporción de melaza se incrementa el contenido de MS en el ensilado. Esta variable también se incrementó $(P<0.05)$ cuando se adicionó harina de arroz como se evidencia en la Tabla 2, la presencia de la harina de arroz incrementa el contenido de MS. El tiempo de maduración no influyó ( $P>0.05)$ en el porcentaje de MS (Tabla 3). Se sugiere un error experimental al momento de tomar el peso de la muestra final, ya que por la pérdida de jugos y material proteico disminuiría su contenido como se aprecia en el proceso. Comparando el contenido de MS del ensilaje de maíz (24.5\%) y del ensilaje de sorgo (28.12\%) reportado por Garcés et al., (2004) con el del estudio (30.6\%) (Tabla 1), se evidencia que la materia seca del ensilaje de Pízamo cuando se utilizó $20 \%$ de melaza fue superior $6.1 \%$ y $2.48 \%$ respectivamente, debido a la cantidad de carbohidratos estructurales que posee el forraje de Pízamo reflejado en la fibra cruda, por ser una especie arbustiva.

En el contenido de proteína presenta una disminución $(\mathrm{P}<0.05)$ a medida que aumenta el tiempo de maduración (Tabla 3), posiblemente porque se hidrolizan hasta aminoácidos y se presenta degradación de alguno de ellos, en especial los del ácido glutámico y aspártico por las descarboxilasas de las plantas 
según lo reportado por Sánchez et al., (1999). Es más alto el contenido de proteína en los tratamientos con harina de arroz (Tabla 2) ya que este alimento aporta un porcentaje de este nutriente a este ensilado (Latorre et al., 2000). Según lo reportado por Sánchez et al., (1999) los porcentajes de proteína en el ensilaje de maíz (7.84\%) y de sorgo (5.99\%) comparado con el del ensilaje de Pízamo (17.2\%) son inferiores por lo tanto se observa la calidad del ensilaje de Pízamo sobre estos dos ensilajes con relación a este nutriente. Es de anotar que los niveles de melaza no influyeron en el contenido de proteína. El contenido de grasa fue similar para todos los tratamientos $(P>0.05)$, no influyeron, los niveles de melaza, ni la adición de la harina de arroz, lo mismo que los tiempos de maduración, se mantiene su contenido hasta el final del estudio (Tablas 1, 2 y 3). Según lo reportado por Garcés et al., (2004) existe un contenido similar de grasa entre el ensilaje de maíz (3.1\%) $y$ el de sorgo (2.94\%) siendo inferiores estos valores al compararse con el contenido en el ensilaje de Pízamo (3.7 a 3.9\%).

Tabla 1. Calidad nutricional (\%) del ensilaje de Pízamo (Erythrina glauca) con los diferentes niveles de melaza

\begin{tabular}{lccc}
\hline \multicolumn{1}{c}{ Variable } & $\mathbf{1 0} \%$ de melaza & $\mathbf{1 5 \%}$ de melaza & $\mathbf{2 0} \%$ de melaza \\
\hline Materia seca & $24.9^{\mathrm{c}}$ & $26.0^{\mathrm{b}}$ & $30.6^{\mathrm{a}}$ \\
Proteína & $16.6^{\mathrm{a}}$ & $16.6^{\mathrm{a}}$ & $16.7^{\mathrm{a}}$ \\
Grasa & $3.9^{\mathrm{a}}$ & $3.9^{\mathrm{a}}$ & $3.8^{\mathrm{a}}$ \\
Fibra cruda & $26.0^{\mathrm{a}}$ & $26.0^{\mathrm{a}}$ & $26.2^{\mathrm{a}}$ \\
ENN & $38.1^{\mathrm{a}}$ & $38.2^{\mathrm{a}}$ & $38.3^{\mathrm{a}}$ \\
Ceniza & $4.1^{\mathrm{a}}$ & $4.1^{\mathrm{a}}$ & $4.1^{\mathrm{a}}$ \\
FDN & $48.2^{\mathrm{a}}$ & $48.3^{\mathrm{a}}$ & $48.6^{\mathrm{a}}$ \\
FDA & $38.0^{\mathrm{a}}$ & $38.0^{\mathrm{a}}$ & $38.0^{\mathrm{a}}$ \\
\hline
\end{tabular}

Letras distintas en la misma fila, son diferentes $(P<0.05)$.

Para el contenido de fibra cruda, se presenta una disminución $(P<0.05)$ cuando se aumenta el tiempo de maduración del ensilaje (Tabla 3), con relación al contenido inicial para el primer mes, la pérdida es de 3.8\%; a los 60 días se disminuye en $5.8 \%$ y finalmente a los 90 días se baja un $12.6 \%$. La pérdida de 
fibra cruda se ocasiona por la descomposición de la parte estructural del forraje por acción de las enzimas producidas en el proceso de fermentación como lo describe Roa et al., (2002). Se mantuvieron similares $(P>0.05)$ los contenidos de fibra cruda con en los tres niveles de melaza en adición o no de la harina de arroz (Tablas 1 y 2 ).

El extracto no nitrogenado (ENN) se mantuvo similar $(P>0.05)$ con los diferentes niveles de melaza y harina de arroz (Tablas 1 y 2), mientras que se incrementó $(P<0.05)$ con el tiempo de maduración (Tabla 3 ), lo cual se debe posiblemente al efecto de la disminución de la fibra cruda, pues este nutriente se disminuye a medida que el ensilaje va madurando. Garcés et al., (2004) reportan porcentajes de ensilaje de maíz (47\%) y de sorgo (45.2\%) siendo superiores estos valores a los del ensilaje de Pízamo encontrados en este estudio, lo cual es lógico por la diferencia que existe en el contenido de proteína del Pízamo entre 15 a 19\% con el de estas dos gramíneas que son de: maíz $7.84 \%$ y sorgo $5.99 \%$, datos reportados por Gutiérrez y Roa, (2003).

El contenido de ceniza fue similar $(P>0.05)$ para todos los tratamientos, no se observó efecto en los niveles de melaza, de harina de arroz y tiempo de maduración (Tablas 1, 2 y 3). Según esta investigación, el contenido de este nutriente fue inferior en el ensilaje de Pízamo (4.1 a 4.2\%) en comparación los ensilajes de maíz y sorgo siendo sus contenidos de $6.9 \%$ y $7.3 \%$ respectivamente, según valores reportados por Garcés et al., (2004).

Los datos de FDN y FDA mostraron un comportamiento similar $(P>0.05)$ en cuanto a los niveles de melaza y harina de arroz (Tablas 1 y 2 ), mientras que estos dos nutrientes disminuyeron $(\mathrm{P}<0.05)$ con el tiempo de maduración (Tabla 3, Figuras 1 y 2). En los porcentajes de FDN se observa una disminución con relación al contenido inicial de 1.7\%, 7\% y 13.7\%, para 30, 60 y 90 días respectivamente (Figura 1). En los porcentajes de FDA se observa una disminución con relación al contenido inicial de 3.4\%, 5.3\% y $7.7 \%$, para 30 , 60 y 90 días, respectivamente (Figura 2). La rápida disminución en el contenido de estos dos nutrientes se debe a la acción del pH y la fermentación láctica de los carbohidratos estructurales por los microorganismos, presentada 
en el tiempo de maduración, ocasiona un rompimiento de la pared celular dejando libre el contenido celular, el cual es más asimilable para los animales.

Tabla 2. Calidad nutricional (\%) del ensilaje de Pízamo (Erythrina glauca) con $y$ sin harina de arroz

\begin{tabular}{lcc}
\hline \multicolumn{1}{c}{ Variable } & CON & SIN \\
\hline Materia seca & $29.1^{\mathrm{a}}$ & $26.6^{\mathrm{b}}$ \\
Proteína & $17.2^{\mathrm{a}}$ & $15.1^{\mathrm{b}}$ \\
Grasa & $3.9^{\mathrm{a}}$ & $3.9^{\mathrm{a}}$ \\
Fibra cruda & $26.0^{\mathrm{a}}$ & $26.0^{\mathrm{a}}$ \\
ENN & $38.2^{\mathrm{a}}$ & $38.3^{\mathrm{a}}$ \\
CENIZA & $4.2^{\mathrm{a}}$ & $4.1^{\mathrm{a}}$ \\
FDN & $48.8^{\mathrm{a}}$ & $48.0^{\mathrm{a}}$ \\
FDA & $38.3^{\mathrm{a}}$ & $37.7^{\mathrm{a}}$ \\
\hline
\end{tabular}

Letras distintas en la misma fila, son diferentes $(P<0.05)$.

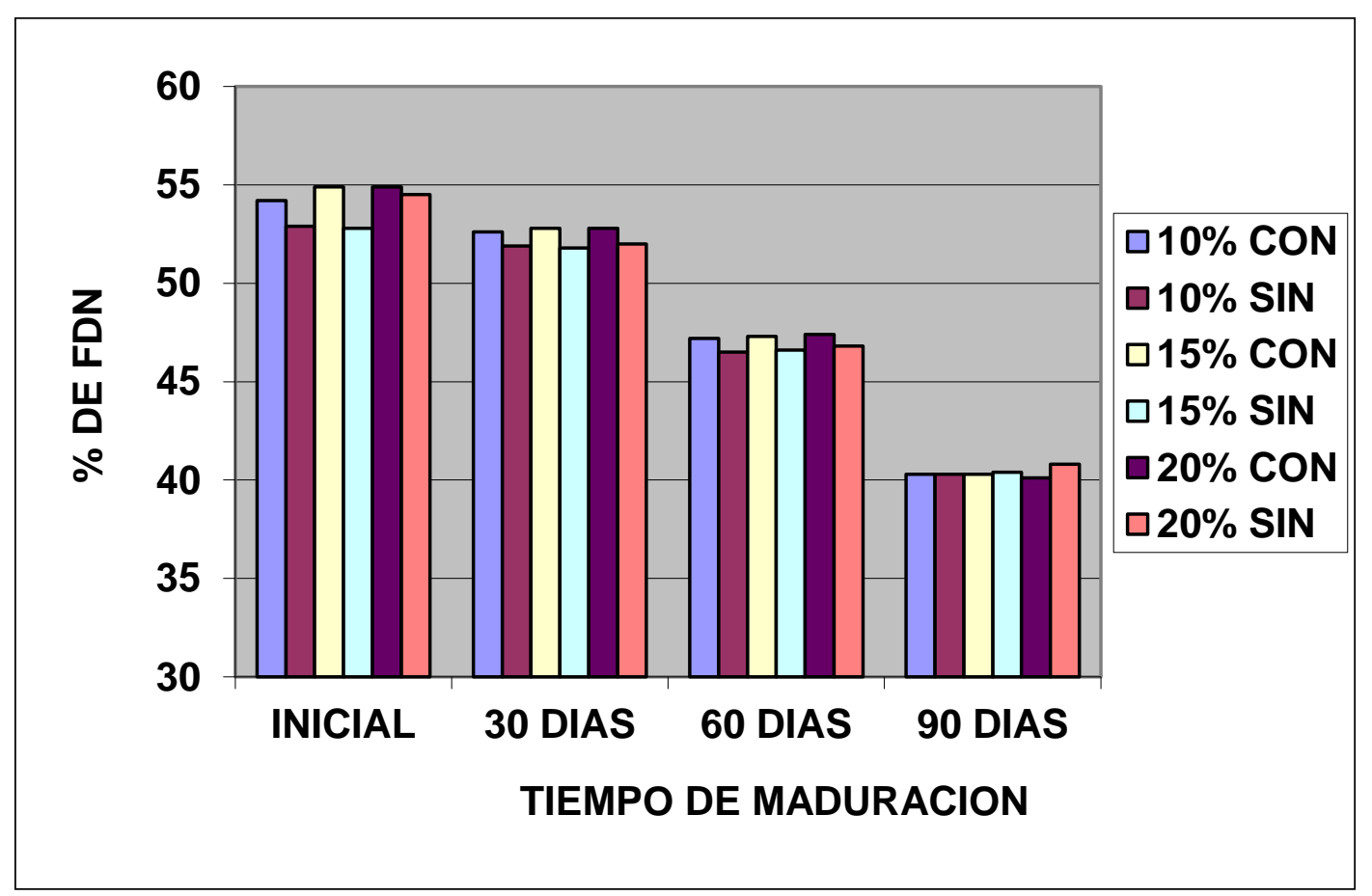

Figura 1. Variación de la fibra detergente neutro (FDN) del ensilaje (Erythrina glauca) en diferentes tiempos

La degradación ruminal de materia seca a las 72 horas (Figura 3) no se afectó con los niveles de melaza y de harina de arroz $(P>0.05)$, mientras que con el 
tiempo de maduración se incrementó $(P<0.05)$, la degradabilidad del ensilaje inicial fue de $46.6 \%$ y después se incrementó $1.9,8.4$ y $14.2 \%$ para los 30,60 y 90 días respectivamente (Tabla 3 y $\mathrm{F}$ igura 3 ). Al comparar estos resultados con los de Roa et al., (2002) quienes encontraron que la DMS a las 72 horas del Pízamo sin ensilar fue de $33.8 \%$. Lo cual indica, que el efecto del ensilaje incrementa en $12.6 \%$ más la degradación inicial, a los 30, 60 y 90 se aumenta en $14.5,21$ y $26.8 \%$ más respectivamente (Tabla 3 y Figura 3 ). El efecto de la fermentación realizada por los microorganismos rompiendo las paredes celulares dejando una mayor del contenido celular el cual es más degradable en el rumen. La DMS en las diferentes horas de degradación fue mínima, observándose un comportamiento similar $(P>0.05)$ en cada una de las horas evaluadas $(6,12,24,48$ y 72) (Figura 4). La DMS fue rápida en las primeras 6 horas, llegando a un $39 \%$, promedio de todos los tratamientos, el incremento en las siguientes horas fue: $2 \%, 8 \%, 11 \%$ y $13,7 \%$, respectivamente (Figura 4 ), lo cual indica que la DMS, fue lenta después de las 6 horas hasta las 72 horas, promedio de todos los tratamientos $52.7 \%$, valor superior con relación al pizamo no ensilado, cuya DMS a las 72 h, fue de $33.8 \%$, según los resultados de Roa et al., (2000) en estudios con este árbol forrajero.

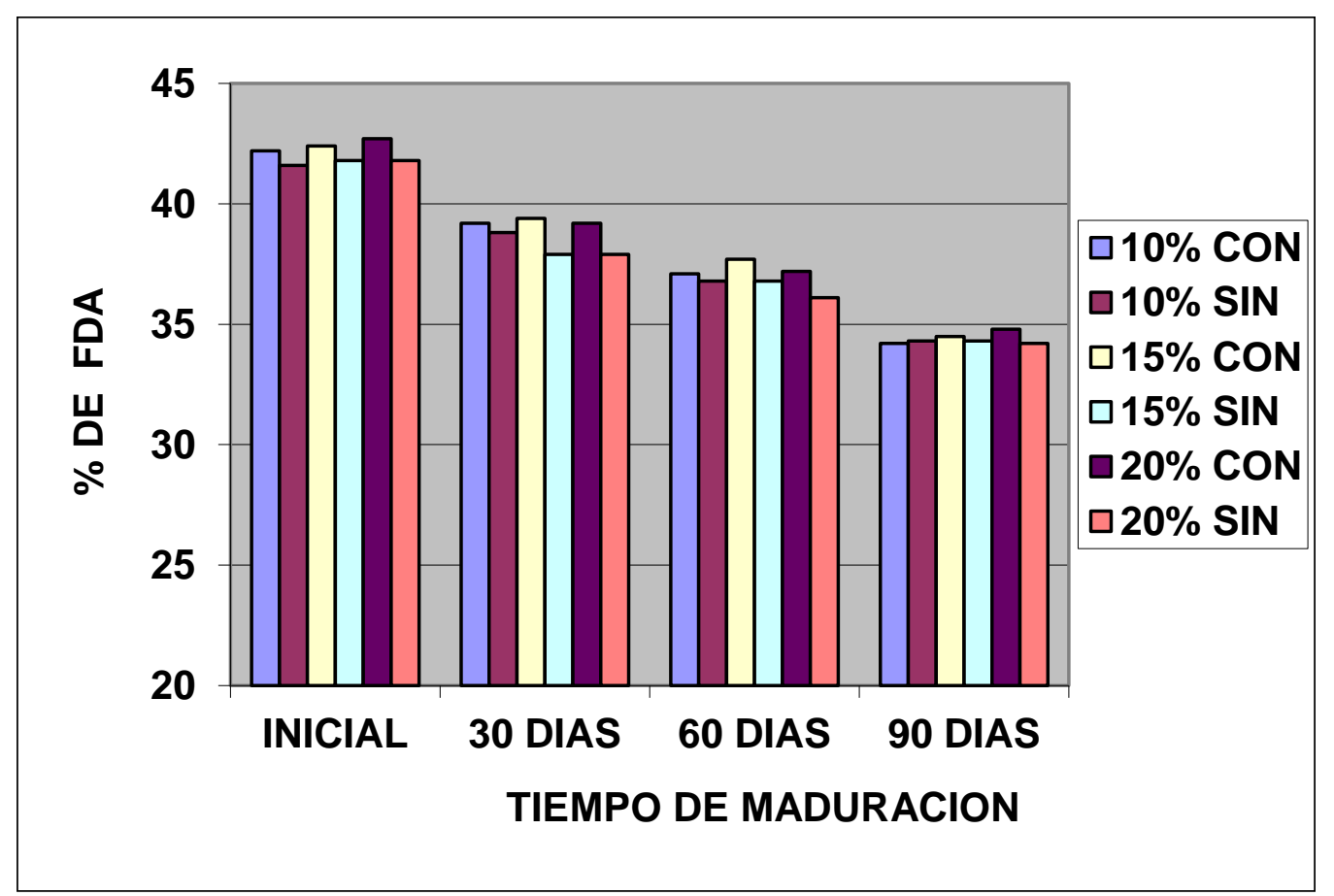

Figura 2. Variación de la fibra detergente ácido del ensilaje (Erythrina glauca) (FDA) en diferentes tiempos 
Tabla 3. Calidad nutricional (\%) del ensilaje de Pízamo (Erythrina glauca) en los diferentes tiempos de maduración

\begin{tabular}{ccccc}
\hline Variable & Inicial & 30 días & 60 días & 90 días \\
\hline Materia seca & $29.2^{\mathrm{a}}$ & $28.7^{\mathrm{a}}$ & $28.6^{\mathrm{a}}$ & $29.0^{\mathrm{a}}$ \\
Proteína & $19.0^{\mathrm{d}}$ & $16.8^{\mathrm{c}}$ & $15.8^{\mathrm{b}}$ & $15.0^{\mathrm{a}}$ \\
Grasa & $3.8^{\mathrm{a}}$ & $3.8^{\mathrm{a}}$ & $3.7^{\mathrm{a}}$ & $3.7^{\mathrm{a}}$ \\
Fibra cruda & $30.8^{\mathrm{a}}$ & $27.1^{\mathrm{b}}$ & $25.0^{\mathrm{c}}$ & $18.2^{\mathrm{d}}$ \\
ENN & $38.3^{\mathrm{d}}$ & $41.2^{\mathrm{c}}$ & $43.2^{\mathrm{b}}$ & $44.3^{\mathrm{a}}$ \\
Ceniza & $4.2^{\mathrm{a}}$ & $4.2^{\mathrm{a}}$ & $4.1^{\mathrm{a}}$ & $4.1^{\mathrm{a}}$ \\
FDN & $54.0^{\mathrm{a}}$ & $52.3^{\mathrm{b}}$ & $47.0^{\mathrm{c}}$ & $40.3^{\mathrm{d}}$ \\
FDA & $42.1^{\mathrm{a}}$ & $38.7^{\mathrm{b}}$ & $36.8^{\mathrm{c}}$ & $34.4^{\mathrm{d}}$ \\
DMS a las 72 horas & $46.4^{\mathrm{d}}$ & $48.3^{\mathrm{c}}$ & $54.8^{\mathrm{b}}$ & $60.6^{\mathrm{a}}$ \\
\hline
\end{tabular}

Letras distintas en la misma fila, son diferentes $(P<0.05)$.

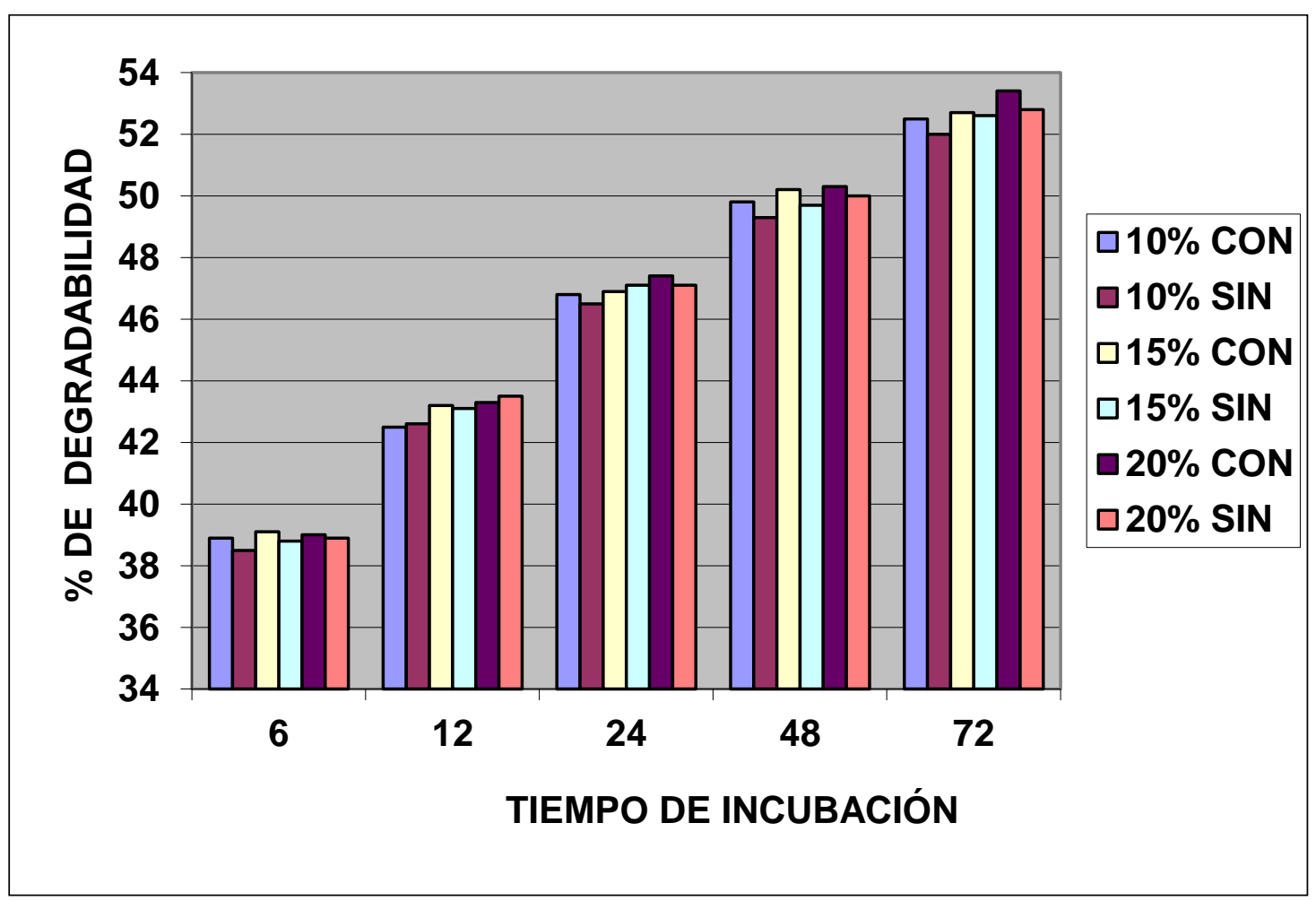

Figura 3. Variación de la degradabilidad ruminal de la materia seca del ensilaje de (Erythrina glauca) a diferentes tiempos de incubación en los tratamientos 


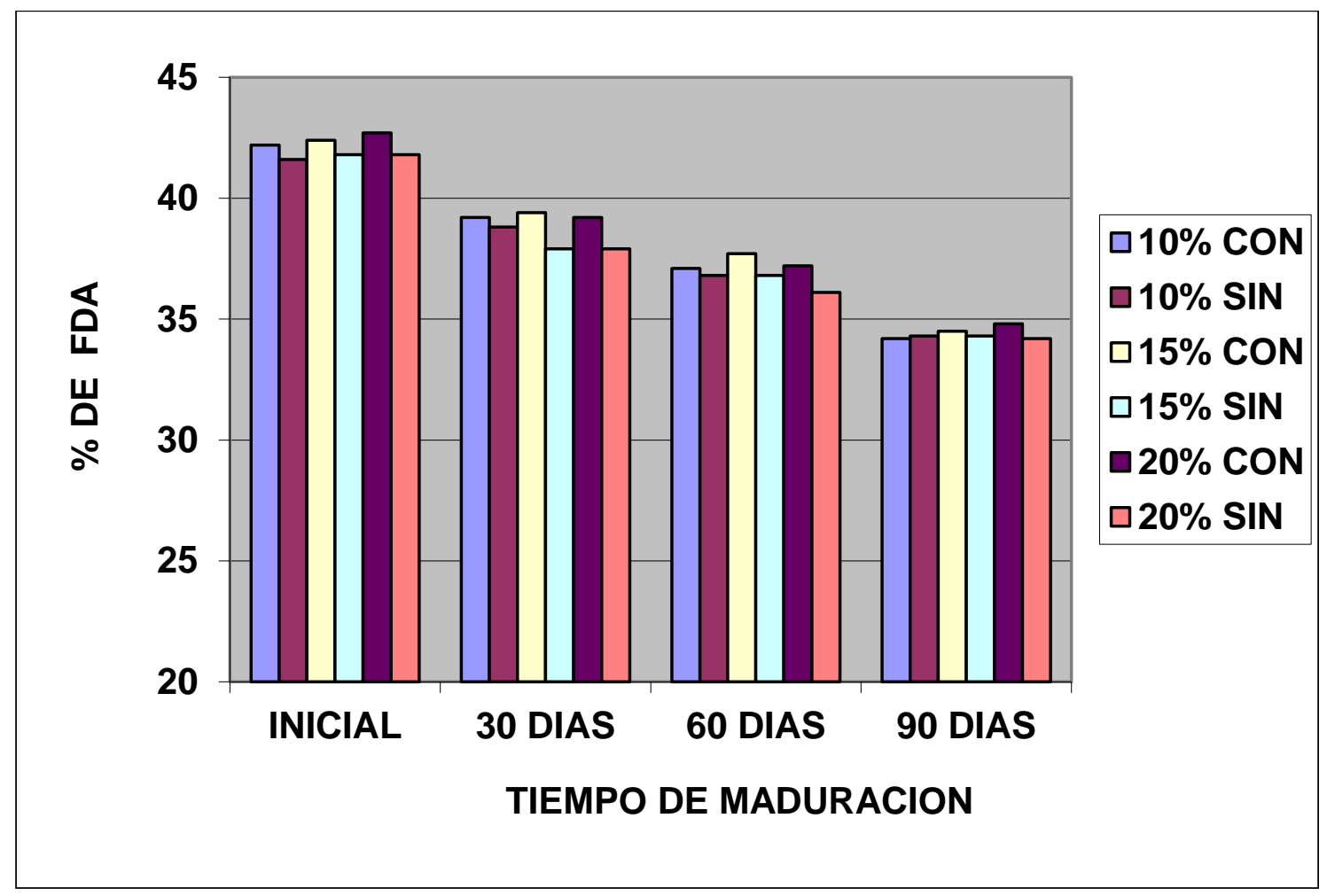

Figura. 4. Variación de la degradabilidad ruminal de la materia seca del ensilaje de (Erythrina glauca) en diferentes horas

\section{CONCLUSIONES}

La materia seca se incrementó en los tratamientos con $20 \%$ melaza y a los que se les adicionó harina de arroz, los tiempos de maduración del ensilaje no influyeron en esta variable. Los diferentes niveles de melaza con y sin harina de arroz y tiempos de maduración evaluados no afectaron el contenido de ceniza y grasa. La fibra cruda, la FDN y la FDA se disminuyeron a medida que se incrementaba el tiempo de maduración del ensilaje lo cual permite deducir que la fermentación realizada por los microorganismos rompe las paredes celulares. Lo contrario sucedió con la DMS a las 72 horas, la cual se fue incrementando a medida que se aumentaba el tiempo de maduración, debido a la mayor disponibilidad del contenido celular.

Se observó perdida de proteína durante el tiempo de maduración del ensilaje, en donde el porcentaje más alto de disminución se presentó a los 90 días de fermentación, igual ocurrió cuando no se les adicionó harina de arroz la proteína fue más baja en comparación con los tratamientos que tenían harina de arroz. 


\section{BIBLIOGRAFÍA}

1. AOAC. Official Methods of Analysis. $18^{\text {th }}$ ed. Washington, DC: Arligton V. A. 2006.

2. Axford R. F., Omed H. M. (eds.) Forage Evaluation in Ruminant. Wallingford: $C A B$ International 2000.

3. Chacón, E. Gerencia de Recursos Alimenticios en Sistemas de Producción con Bovinos a Pastoreo. En: I Cursillo "Uso de Recursos Alimenticios para la Producción de Bovinos a Pastoreo" Editores: A. Torres, I Entrena y E. Chacón. FONAIAP - Est. Exp. Trujillo pp 1-28. 2000.

4. Flores O. I., Bolivar M., Botero J., Ibrahim M. Parámetros nutricionales de algunas arbóreas leguminosas y no leguminosas con potencial forrajera para la suplementación de rumiantes en el trópico. Centro Agronómico Tropical de Investigación y Enseñanza, Turrialba, Costa Rica. 2001.

5. Garcés A., Berrio M., Ruíz L., Alzate S., D, León, J., Builes A. Ensilaje como fuente de alimentación para el ganado Revista Lasallista de Investigación [en línea], [fecha de consulta: 7 de Septiembre de 2010]. Disponible en: http://redalyc.uaemex.mx/redalyc/src/inicio/ ArtPdfRed.jsp?iCve=69511010 ISSN. 1794 - 4449. 2004

6. García, D. E.; Medina, M. G. Composición química, metabolitos secundarios, valor nutritivo y aceptabilidad relativa de diez árboles forrajeros. Zootecnia Trop., 24 (3): 233 - 250. 2006.

7. García, D. E.; Medina, M. G.; Humbría, J.; Domínguez, C. E.; Baldizán, A, Cova, L. J.; Soca, M. Composición proximal, niveles de metabolitos secundarios y valor nutritivo del follaje de algunos árboles forrajeros tropicales. Arch Zootecnia; 55 (212): 373 - 384. 2006.

8. Godden S. M., Lissemore K. D., Kelton D. F., Lumsden J. H., Leslie K. E., Walton J. S. Analytic validation of an infrared milk urea assay and effects of sample acquisition factors on milk urea results. Journal of Dairy Science 83: 435 - 442. 2000.

9. González E., Cáceres O. A. Valor nutritivo de árboles, arbustos y otras plantas forrajeras para rumiantes. Est. Exp. de Pastos y Forrajes "Indio Hatuey” Matanzas, Cuba. Vol. 25. № 1. pp. 15 - 20. 2002. 
10. Gutiérrez R., Roa M. Determinación de algunos compuestos químicos en cuatro plantas arbóreas forrajeras, Colombia, Rev. Col. Ciencias Pec. vol: 16 fasc: 2: 155 - 160. 2003.

11. Instituto Colombiano Agropecuario (ICA). Ensilaje: alternativa sostenible para la producción de ganado en clima frío. En Manual ganadero actual. Grupo latino Ltda., Bogotá, Colombia. p. 1135 - 1143. 2004.

12. Krause K. M., Combs D. K., Beauchemin K. A. Effects of increasing levels of refined cornstarch in the diet of lactating dairy cows on performance and ruminal pH.2003. Journal of Dairy Science. 86: 1341-1353. 2003.

13. Latorre R. S., Alvarado G. J., Moreno R. G., Rojas G. J. Subproductos agrícolas para nutrición de rumiantes; alternativas de utilización mecanizada. CORPOICA, Boletín de investigación n.1. Bucaramanga, Colombia. 120p.

14. Lemus L. H., Lemus V. E. Plantas de uso forrajero en el trópico cálido y templado de Colombia. Universidad de los Llanos Villavicencio, Colombia. P. 360. 2004.

15. Llano G., Ramírez D., Mahecha L. Alternativas nutricionales para los sistemas de producción bovina de carne en Colombia. En: Bioquímica, nutrición y alimentación de la vaca. Universidad de Antioquia, Facultada de Ciencias Agrarias, Medellín, Colombia. P.303 - 330. 2005.

16. Mertens D. R. Journal of AOAC International 85: 1217-1240. 2002.

17. Narváez, N. Magnitud y tasa de fermentación in vitro de la materia seca y degradación de la fibra en diferentes especies arbóreas tropicales con uso potencial como forraje en Colombia. [Tesis de Maestría]. Palmira: Facultad de Ciencias Agropecuarias; Programa de Zootecnia, Universidad Nacional Sede Palmira; 2000

18. Narváez N., Lascano C. Caracterización química de especies arbóreas tropicales con potencial forrajero en Colombia. Pasturas Tropicales; 26: 1 - 8. 2004.

19. Roa M. L., Céspedes D., Galeano J., Muñoz. J., Muñoz R. Utilización de árboles forrajes para la alimentación de ganado en el pie de monte llanero, Informe Técnico n. 2, Unillanos-Colciencias, Villavicencio, Colombia. 240 p. 1999. 
20. Roa M. L., Céspedes D. A. Alimentación de ovinos con árboles forrajeros. Rev. Agricultura de las américas. 271: 15 - 19p. 1999.

21. Roa M. L., Galeano J. R., Muñoz J. Suplementación de vacas doble propósito con Morus alba y Erythrina glauca en época seca en subregión del pie de monte Llanero. Rev. Orinoquia. 6: 1: 70 - 82p. 2002.

22. Roa M. L. Contenido nutricional de forrajes y alimentos para animales. Manual de Roa M.L. Villavicencio: Universidad de los Llanos, Escuela de Ciencias Animales. Material de Apoyo a la Docencia. 2004.

23. Sánchez M., Delatorre L., García G. Ensilaje como alternativa sostenible para producción bovina en las áreas rurales del Distrito Capital. Ed. DAMA, Corpoica, Bogotá, Colombia. 89p. 1999. 